\title{
Perspectivas ecofeministas de la ciencia y el conocimiento La crítica al sesgo andro-antropocéntrico
}

\author{
Ecofeminist Perspectives on Science and Knowledge \\ The Critic of Andro-anthropocentric Biais
}

\begin{abstract}
Resumen: Este artículo sostiene que la crítica feminista de la ciencia alcanza su máxima intensidad con la teoría ecofeminista porque, en ésta, el análisis del androcentrismo conecta con el intento de superación del antropocentrismo. Considerando que androcentrismo y antropocentrismo se hallan profundamente ligados, el ecofeminismo busca un modelo científico empático que reemplace el paradigma del dominio de la naturaleza propio del complejo tecno-científico hegemónico. Pero, para lograr con éxito este cometido, sus teóricas deben evitar caer en una mística biocéntrica que termine negando los derechos de las mujeres sobre sus propios cuerpos y en un relativismo cultural que debilite su objetivo de superación del andro-antropocentrismo y disuelva la realidad del cuerpo sufriente en el espacio ideal del discurso. Palabras clave: género, ciencia, ecofeminismo, androcentrismo, antropocentrismo.
\end{abstract}

\begin{abstract}
This article argues that feminist critique of science is at its strongest in ecofeminist theory because in this theory, the analysis of androcentrism is linked to an attempt to overcome anthropocentrism. Considering that androcentrism and anthropocentrism are deeply linked, ecofeminism seeks an empathic scientific model that replaces the paradigm of the mastery of nature associated with an hegemonic technoscientific framework. But in order to successfully achieve this goal, theorists must avoid falling into a biocentric mystique that ends up denying women's rights over their bodies. They must also be wary of cultural relativism which does not prioritise overcoming andro-anthropocentrism and uses the ideal space of discourse to ignore the reality of the suffering body.
\end{abstract}

Key-words: Gender, Science, Ecofeminism, Androcentrism, Anthropocentrism.

Abordar el tema de las relaciones entre ciencia, conocimiento y género requiere comenzar recordando que las mujeres han sido excluidas del conocimiento a lo largo de la Historia. A menudo se ha utilizado argumentos "científicos" para justificar esta exclusión y

Recibido: 03/04/2017. Aceptado: 10/07/2017.

* Profesora Titular de Filosofía Moral de la Universidad de Valladolid. aliciahelda.puleo@uva.es Líneas de investigación: Los valores éticos y las ideas políticas de la Ilustración, la praxis emancipatoria derivada de ellos y diversos aspectos de Filosofía Moral y Política relacionados con los principios de libertad e igualdad de las democracias modernas: la conceptualización de la sexualidad, la teoría feminista y de género, la bioética y la ética ambiental. Entre sus últimas publicaciones, corresponde destacar: Ecología y Género en diálogo interdisciplinar (2015) y «Donne e mutamento sociale», DEP, Università Ca’Foscari Venezia, $\mathrm{n}^{\circ} 28$ (2015). El presente trabajo se enmarca en el proyecto de investigación Prismas filosófico-morales de las crisis (FFI2013-42935-P del Plan Nacional I+D; MICIN-MINECO) del que forma parte. 
cuando alguna mujer realizaba aportaciones de gran valor al conocimiento se ignoraban, se devaluaban o se adjudicaban a otro (García Dauder y Pérez Sedeño, 2017). Hasta la misma Ilustración mantuvo posiciones encontradas en cuanto a la inclusión de las mujeres en algo que era clave para su proyecto de progreso del espíritu humano: la educación y el desarrollo de las ciencias y las técnicas (Amorós, 1997; Puleo, 2000; Roldán, 2013). Todavía hoy subsiste una importante brecha de género en el mundo de la ciencia. ${ }^{1}$ Puede decirse que la incorporación de las mujeres al conocimiento científico se produce entre la integración normalizadora y la crítica a los sesgos androcéntricos del corpus heredado.

En lo que se refiere a este último aspecto, considero que la teoría ecofeminista constituye uno de los desarrollos más prometedores del pensamiento feminista para los tiempos del cambio climático. Su relación con la ciencia es estrecha y, al mismo tiempo, profundamente crítica. Por un lado, puede constatarse que en su mismo origen es deudora del conocimiento científico. Por otro, se advierte su potencial innovador y disruptivo derivado de la combinación de la crítica al androcentrismo y la crítica al antropocentrismo, una unión que, ya desde las pensadoras proto-ecofeministas, lleva a una posición que no se limita a un empirismo feminista que reclame la admisión de más mujeres en la ciencia y la corrección del sexismo y el androcentrismo mediante una aplicación correcta de la metodología científica. La crítica ecofeminista se despliega en un abanico de posiciones que van desde lo que se conoce como standpoint feminism o epistemología del punto de vista, con marcos conceptuales y visiones alternativas desde la experiencia de la opresión de género, hasta los enfoques más emparentados con la postmodernidad que dan énfasis a la diversidad cultural.

En estas líneas, me referiré en primer lugar a la influencia de la ciencia en el surgimiento de la teoría ecofeminista en los años setenta del siglo XX. Pasaré después a examinar las aportaciones críticas de esta teoría con respecto al conocimiento científico. Agrupo estas aportaciones en torno a dos núcleos fundamentales interrelacionados: la defensa del cuerpo de las mujeres frente a una tecnociencia que se experimenta como agresiva, manipuladora y amenazante y la detección de modelos patriarcales en la construcción del objeto y el sujeto de la ciencia en la Modernidad.

\section{El origen científico}

El surgimiento del ecofeminismo como punto de contacto de las reivindicaciones de las mujeres con las metas del naciente movimiento ecologista se dio en los años setenta del pasado siglo por una conjunción de factores de orden social e intelectual. Entre estos últimos,

1 Así, por ejemplo, el informe presentado el 7 de febrero de 2017 por la Unidad de Mujeres y Ciencia del Ministerio de Economía, Industria y Competitividad español señala que, en el Área de Ciencias Naturales, 30 comisiones técnicas de evaluación de Proyectos de I+D Excelencia, Proyectos de I+D+i de Retos de la Sociedad y Proyectos Jóvenes sin vinculación o con vinculación temporal presentaban infrarrepresentación de mujeres. Según el criterio de equilibrio de género, se considera que hay infrarrepresentación cuando un sexo no está representado en al menos el $40 \%$ de las personas que integran la comisión. Ninguna de las comisiones tenía infrarrepresentación de hombres. La tasa de éxito en las convocatorias de proyectos continúa siendo menor en el caso de las mujeres. Asimismo, el porcentaje de investigadoras y catedráticas es del 21\%, una proporción muy baja, similar a la del resto de países europeos. Este informe fue elaborado a partir de datos de la Agencia Estatal de Investigación. (Científicas en Cifras 2015. Estadísticas e indicadores de la (des)igualdad de género en la formación y profesión científicas, 2017). 
hay que destacar el impacto de un importante estudio antropológico sobre la relación entre las mujeres y la Naturaleza, el interés de algunas pensadoras y activistas feministas en la ciencia de la Ecología y en las proyecciones demográficas y ambientales que auguraban un futuro catastrófico para la humanidad. El influyente artículo de la antropóloga Sherry Ortner (1972) sobre las evidencias empíricas de la existencia, en el imaginario de las diferentes culturas humanas, de una constante asociación de la figura de la Mujer a la de la Naturaleza puede considerarse como un punto de partida clave para la teoría ecofeminista, tanto en sus corrientes esencialistas como constructivistas. La hipótesis de este estudio buscaba dar una explicación al origen de la subordinación universal de las mujeres y la encontraba en el hecho de que éstas realizaban funciones y ocupaban espacios de mediación entre Naturaleza y Cultura: transformación de lo crudo en lo cocido y procreación y crianza de los niños que los sacaba de un estado natural cercano a la animalidad para integrarlos en el logos. Puesto que la Cultura era considerada por todos los pueblos como superior a la Naturaleza, el estatus degradado de ésta se extendía al colectivo femenino ${ }^{2}$. Cierto es que, si atendemos al contexto de descubrimiento tal como requiere la perspectiva CTS, el estudio de Ortner sólo había sido posible gracias a las reflexiones previas de una filósofa feminista. El Segundo Sexo de Simone de Beauvoir, publicado en 1949, ofrecía, sin lugar a dudas, el marco que posibilitó las preguntas que guiaron su investigación y la hipótesis que planteara. Pero lo que en Beauvoir era fruto de un estudio erudito, filosófico, basado en fuentes bibliográficas, en Ortner se convierte en Antropología Cultural que revertirá a su vez, con resultados diferentes, en la filosofía feminista y en la ecofeminista.

La nueva ciencia de la Etología, consolidada gracias a las investigaciones de Konrad Lorenz, también ejerció un importante influjo, no exento de polémica ${ }^{3}$, en el pensamiento ecofeminista. Dejando atrás el conocimiento estereotipado de los animales producido en los laberintos artificiales del conductismo, la Etología mostraba la vida silvestre en una realidad no constreñida por reglas humanas. Las teóricas ecofeministas no tardarán en poner los nuevos conocimientos etológicos en relación con las propuestas del psicólogo británico Richard Ryder y del filósofo utilitarista australiano Peter Singer. Recordemos, asimismo, que en 1970 Richard Ryder forjó el término speciesism ${ }^{4}$ para referirse al prejuicio de especie que lleva a no incluir a los animales en la consideración moral a pesar de tratarse de seres capaces de sufrir. Continuó usándolo en las publicaciones que realizó con el grupo de filósofos de Oxford al que se uniera posteriormente. Peter Singer se sirvió de este término en su libro Animal Liberation, publicado en 1975. Esta obra marca el inicio del movimiento animalista internacional y es contemporánea de la formación de los primeros grupos ecofeministas en EE.UU. El "especismo" será incluido en las intersecciones

2 Hacia mediados de los noventa del siglo XX, por la influencia del post-estructuralismo en la Antropología, Sherry Ortner (1996) modera sus tesis de los setenta, sin desestimarlas por completo. Reconoce la dificultad de afirmar con carácter universal su hipótesis, pero la mantiene en lo que concierne a Occidente y gran parte de Oriente.

3 Cf. Collard (1988) sobre la universalización de una supuesta naturaleza agresiva de los seres humanos en Konrad Lorenz.

4 El Oxford English Dictionary lo incluye a partir de su edición de 1985. La RAE aún no ha aceptado su traducción castellana ("especismo"), a pesar de que es ampliamente utilizada en las obras de Ética Animal del ámbito hispanohablante. 
centrales del género abordadas por el ecofeminismo, junto al sexismo, racismo, clasismo y otras formas de opresión por razón de orientación sexual o discapacidad.

La labor investigadora y de divulgación de la bióloga estadounidense Rachel Carson ocupa un lugar central en el pensamiento ecofeminista. Una de sus teóricas más tempranas, Mary Daly, la llamó "Casandra del ecologismo" por su obra Silent Spring (1962), obra en la que advertía de los peligros, tanto para los animales silvestres como para los humanos, de la fumigación con DDT y su transmisión a través de la cadena trófica. El poético título de la obra se refería a la muerte de los pájaros debido a los insecticidas. Enferma de cáncer de mama, se definió como una víctima de esa peculiar guerra contra la naturaleza llevada a cabo por la agricultura industrial ${ }^{5}$. La reacción de las grandes empresas químicas fue muy agresiva. Trataron de restarle credibilidad como científica, utilizando estereotipos de género que la presentaban como una solterona mística y sensiblera (Guerra, 2004). Tras su fallecimiento, su figura fue debidamente reconocida y recordada por el movimiento ecologista y ecofeminista como una pionera que desveló la vulnerabilidad humana que genera la destrucción del ecosistema.

Finalmente, hay que señalar que puede considerarse determinante para el surgimiento de las teorías ecofeministas la preocupación ecologista por la insostenibilidad del crecimiento descontrolado de la población mundial y la imposibilidad de la expansión económica indefinida en un planeta. Dos de los estudios más influyentes que abordaron estas temáticas fueron The Population Bomb (1968), libro de Paul Ehrlich, profesor en la Universidad de Standford, y el informe Limits to Growth de 1972, obra de un equipo de investigación del Instituto Tecnológico de Massachusetts, entre cuyos miembros se encontraba la científica ambiental Donella Meadows. Françoise d'Eaubonne, teórica del círculo de Simone de Beauvoir, creó el término "écofeminisme" en 1974 y comenzó el desarrollo sistemático de esta corriente basándose justamente en las proyecciones de la ciencia que planteaban la insostenibilidad del crecimiento indefinido de la población mundial y de la economía, dada la imposibilidad de alimentar a tantos millones de seres humanos sin dañar las bases ecológicas de la vida en la Tierra, superando su capacidad de regeneración. D’Eaubonne conectará estas previsiones científicas con las demandas feministas de control sobre el propio cuerpo (D’Eaubonne, 1997). Advierte que si las mujeres no hubieran sido sometidas, a través de los siglos, a la maternidad forzada, no existiría el problema contemporáneo de la sobrepoblación: "En un mundo, o simplemente un país, donde las mujeres (y no, como puede ser el caso, una mujer) estuvieran realmente en el poder, su primer acto habría sido limitar y espaciar los nacimientos. Desde hace mucho tiempo, desde mucho antes de la superpoblación, es lo que siempre han intentado hacer" (D'Eaubonne, 1997, 42). En consonancia con las propuestas feministas de la época, consideró positivos los avances farmacéuticos en el terreno de la contracepción. La solución que propone a la preocupación ecologista sobre la superpoblación consiste, como lo hiciera Simone de Beauvoir, en dar libertad a las mujeres para decidir si desean ser madres. Pero su visión ecológica la lleva a ver las conexiones entre las barreras que encuentran las mujeres para controlar su fertilidad y la necesidad de nuevos consumidores propia de un sistema productivista basado en el crecimiento sin límites de

5 Observemos que el glifosato, utilizado actualmente como herbicida, es un derivado del agente naranja tristemente conocido por su uso como arma durante la guerra del Vietnam. 
la demanda. Propone, por tanto, avanzar hacia un mundo post-patriarcal despojado de la obsesión de poder que subyace al productivismo: "La falocracia está en la base misma de un orden que no puede sino asesinar a la Naturaleza en nombre del beneficio, si es capitalista, y en nombre del progreso, si es socialista" (D’Eaubonne, 1997, 51). Denuncia, pues las falsas promesas de felicidad a través del consumo por no ser sino "una estafa al tiempo, que es la trama de la vida; a la sensibilidad, que es su valor; una frustración gigantesca, planetaria, monstruosa" (D'Eaubonne, 1997, 48). El humanismo que plantea D'Eaubonne incorpora el ideal feminista de sororidad y las demandas de libertad e igualdad de las mujeres en un marco de comprensión ecologista que denuncia el industrialismo, un modelo devastador de la Tierra e incompatible con la búsqueda de una vida satisfactoria.

\section{El cuerpo de las mujeres: ese campo de batalla ${ }^{6}$}

Por su papel en la reproducción de la especie, las mujeres han sido sometidas a un control intenso a lo largo de la Historia. A partir de la Ilustración, la utilización de argumentos biologicistas para acotar el espacio legítimo de desempeño de actividades de las mujeres cobró gran importancia. Era el relevo secular de las antiguas justificaciones religiosas (Puleo, 2000). El pensamiento feminista se vio obligado, por lo tanto, a esforzarse en desmontar el discurso de los llamados "médicos-filósofos" que, basándose en la oposición cerebro/ genitales, adjudicaban a los varones la tarea de hacer avanzar la civilización y a las mujeres la de perfeccionar la especie. Por esta división de funciones, el mundo del saber quedaba reservado a los primeros. A las mujeres se les dejaba el ámbito doméstico, debidamente mejorado por la nueva disciplina de la Higiene y el reemplazo del confesor por el médico de cabecera. Tras esta primera batalla, el feminismo se dedicó en la segunda mitad del siglo XX a examinar las formas en que la opresión patriarcal se ejercía sobre los cuerpos. El concepto foucaultiano de "biopolítica" (Foucault, 1974), si bien en este autor era utilizado sólo marginalmente para referirse a la histerización del cuerpo de las mujeres, facilitó el reconocimiento académico de las interpretaciones feministas que mostraban la conexión entre discurso científico y política, entendida esta última en un sentido amplio frankfurtiano.

Por otra parte, puede decirse que los estudios CTS han hecho del cuerpo un tema privilegiado de su reflexión por influencia del feminismo (Pérez Sedeño y Ortega Arjonilla, 2014). No se trata de un cuerpo uno, sino múltiple, construido por las interacciones con el medio y por la misma actividad científica. Entre los múltiples avances en la investigación sobre el androcentrismo de la ciencia, corresponde señalar que la perspectiva de género en los estudios de la Medicina ha permitido mostrar ciertas inadecuaciones terapéuticas debido a la preeminencia de modelos de estudio masculinos (Valls-Llobet, 2009, Prendergast, Onishi, Zucker, 2014). Así, se ha reclamado mayor atención a la morbilidad diferencial y a los factores de riesgo específicos de las mujeres.

En tanto heredera de las preocupaciones del feminismo de la segunda ola, la teoría ecofeminista aborda el tratamiento del cuerpo de las mujeres en tres dimensiones funda-

6 Inspirada por las demandas y los estudios feministas, en 1989, la artista plástica estadounidense Bárbara Krugger realizaba Your body is a battleground (Tu cuerpo es un campo de batalla), una obra que se convertiría en un ícono del feminismo. 
mentales: la iatrogenia en la Ginecología, el impacto en la salud femenina de un medioambiente saturado de sustancias químicas tóxicas y las nuevas tecnologías reproductivas. En el mismo título de una de las obras pioneras del ecofeminismo, Gyn/Ecology (1978) de Mary Daly, constatamos la preocupación por la Ginecología. En la introducción, Daly se refiere a Françoise d'Eaubonne como la creadora del concepto mismo de "ecofeminismo" pero advierte que, a diferencia de la pensadora francesa, los dos focos de su obra serán la iatrogenia y el control masculino sobre el cuerpo de las mujeres a través de la ciencia y de la Teología. Representante de la corriente esencialista del ecofeminismo, Daly sostiene que las mujeres poseen una conciencia biofílica que puede oponerse a una ciencia y una técnica fascinadas por el poder de Thanatos. La autora se muestra consciente de los riesgos de la carrera nuclear durante la Guerra fría y como especialista en Religión y Teología, denuncia la polución de las mentes que subyace, a su juicio, a la deriva suicida de la Civilización. Denigradas durante siglos por ser concebidas como meros cuerpos y criaturas emocionales frente a los varones, autodefinidos como razón y espíritu, las mujeres pasan en esta obra a ser portadoras del Eros, del valor del cuidado de la Vida. Los tradicionales pares de opuestos razón/emoción, mente/cuerpo y Cultura/Naturaleza son mantenidos pero su valor se trastoca. Los que eran considerados inferiores y asociados a las mujeres serán concebidos como la única promesa de futuro para la humanidad.

Con respecto a la Medicina, Daly participa del interés propio del feminismo de la época en el que grupos estadounidenses como Boston Women's Health Book Collective se hallaban en búsqueda de una Ginecología en la que las mujeres no fueran meras pacientes constreñidas a la obediencia. El trabajo de este grupo había cristalizado en 1973 en el manual Our bodies, our selves (1973) que marca un antes y un después de la aproximación feminista al cuerpo femenino. Su meta era contribuir a la justicia reproductiva y su característica principal el recoger no sólo el conocimiento profesional experto sino también la experiencia de las usuarias a través del método feminista del grupo de autoconciencia ${ }^{7}$. Tanto en su primera edición como en las siguientes, la focalización analítica y el reduccionismo habituales de la Medicina se atenúan con un enfoque más holístico que atiende a todos aquellos aspectos que pueden sustituir o ayudar a los tratamientos farmacéuticos y quirúrgicos: alimentación, tipo de vida, actitudes emocionales, etc. Para cada patología se presentan las distintas opciones terapéuticas y sus ventajas e inconvenientes, acercando la Ginecología a un saber plural y colaborativo que pretende independizarse de los dogmas y de las presiones de las grandes compañías farmacéuticas, dando a las mujeres mayor poder de decisión sobre sus propios cuerpos.

Un aspecto muy importante de la crítica ecofeminista al complejo tecnocientífico es el de los efectos de la toxicidad ambiental en las mujeres y en su salud reproductiva, así como en niños y niñas. Estos son particularmente vulnerables porque aún no se ha desarrollado su sistema inmunológico. El ecofeminismo, como forma del llamado "ecologismo de los pobres" ${ }^{8}$ ha denunciado en numerosas ocasiones que en zonas agrícolas fumigadas, nume-

7 Prueba del éxito de esta obra son los más de cuatro millones de ejemplares vendidos en su primera edición, así como su traducción a 29 idiomas.

8 Este concepto ha sido forjado por el economista Joan Martínez Alier para referirse a aquellos movimientos ecologistas que no se autodenominan como tales pero realizan un activismo claramente ecológico al defender sus intereses inmediatos. 
rosos niños nacen con malformaciones o presentan una alta incidencia de enfermedades tan graves como la leucemia. Los estudios clínicos han mostrado que el cuerpo de las mujeres, por sus ciclos hormonales y por tener una mayor proporción de grasa que el de los hombres, funciona como un bio-acumulador químico de toxinas. El incremento de los cánceres ginecológicos (de mama y de útero) se encuentra vinculado a la proliferación ambiental de xenoestrógenos, compuestos químicos similares al estrógeno, que se hallan presentes en los pesticidas organoclorados, los plásticos, los conservantes de cosméticos, dioxinas de incineradoras, etc. (Valls-Llobet, 2015). La praxis de algunos grupos ecofeministas ha intentado romper el sorprendente silencio que se mantiene sobre las consecuencias de la contaminación medioambiental para las mujeres. En esta problemática se constata una intersección de clase y hasta de raza, ya que las más afectadas suelen ser campesinas pobres, indígenas o trabajadoras de industrias contaminantes en las que a menudo se concentran miembros de minorías étnicas.

Algunas teóricas ecofeministas, como la alemana Maria Mies, han rechazado las nuevas tecnologías reproductivas por considerarlas contrarias a la ética. Su ecofeminismo, basado, como el de Vandana Shiva, en el principio de la santidad de la Vida, la llevará incluso a cuestionar las prácticas anticonceptivas en sí mismas (Mies y Shiva, 1998) y a militar contra la legalización de la eutanasia en Australia. Este ecofeminismo biocéntrico que apela al sentido de lo sagrado aplicado a la Naturaleza es, a mi juicio, altamente problemático para el feminismo. Por ello, he propuesto un ecofeminismo de raíz ilustrada basado en el principio de la calidad de la vida, lo cual permite rechazar la hybris tecnocientífica favorecida por la globalización neoliberal sin renunciar a los beneficios de la ciencia y de la técnica cuando se cumple el principio de precaución y se atiende a la dignidad, al bienestar y a la disminución del sufrimiento. Desde esta posición, las NTR pueden ser criticadas cuando implican daños, riesgos, abusos y/o mercantilización, como suele suceder, por ejemplo, en el caso de la hormonación para la donación de óvulos ${ }^{9}$. La ciencia no es el enemigo a abatir, sino una aproximación a la realidad que es necesario mejorar. Tampoco lo es el legado ilustrado que tan acerbamente critica Shiva (1995). La libertad y la igualdad de las mujeres en el siglo XXI necesitan de ambos.

\section{El dualismo sujeto/objeto y la posibilidad de un conocimiento empático de la naturaleza}

La teoría del standpoint feminism (Hartsock, 1983) sostiene que las mujeres, como grupo oprimido, se encuentran en una posición privilegiada para captar y comprender aspectos de la realidad que permanecen invisibles para los miembros del grupo dominante. La pensadora ecofeminista belga Andrée Collard, discípula de Mary Daly, sostiene: "Women's experience with oppression and abuse, as well as their experience of mothering, can make them more sensitive to the oppression and abuse of nature, as well as better situated to remedy it"10 (Collard, 1988, 138). Tal era también la convicción de algunas pensadoras sufragistas -ver-

9 Las "donantes" reciben una suma de dinero "por las molestias" sin que, por lo general, se les dé suficiente información sobre los riesgos y el carácter del proceso.

10 "La experiencia de opresión y abuso sufrida por las mujeres, así como su experiencia con los cuidados maternales, pueden hacerlas más sensibles a la opresión y al abuso de la naturaleza, y mejor situadas para ponerles remedio" (Mi traducción). 
daderas ecofeministas avant la lettre- que consideraron a mujeres y animales como víctimas de la violencia patriarcal. No sólo observaron que ambos eran objeto de malos tratos no sancionados por la justicia en el ámbito doméstico, sino que vieron conexiones entre el creciente carácter agresivo de la Ginecología y el auge de la experimentación con animales. A finales del siglo XIX, advirtieron una tendencia a practicar cada vez más operaciones de histerectomía y que este incremento era paralelo al auge de la vivisección animal. Denunciaron también el tratamiento que numerosos médicos daban a las mujeres pobres en los hospitales, su falta de respeto cuando las utilizaban para enseñar casos de enfermedades a los estudiantes y su negativa a administrarles anestesia bajo el pretexto de que, por su rusticidad, no eran suficientemente sensibles para experimentar dolor (Bianchi, 2015). En 1875, la leader sufragista Frances Power Cobbe creó la primera liga para la abolición de la vivisección. El Brown Dog Affair ${ }^{11}$ llevaría incluso a enfrentamientos callejeros entre sufragistas y estudiantes de Medicina.

El fenómeno altamente feminizado de la oposición a la vivisección no se daba solamente en Gran Bretaña. En Francia ${ }^{12}$, la feminista Marie Huot, presidenta de la Ligue Populaire contre la Vivisection, se enfrentará a Pasteur y sostendrá en sus conferencias que las mujeres poseen un instinto maternal que las lleva a asistir a todo aquel que sufre (Traïni, 2011). En la segunda mitad del siglo XIX, "para los fisiólogos, la vivisección era el símbolo de la libertad de la ciencia, un principio que no permitía excepciones; para las antiviviseccionistas era el símbolo de la separación entre la ética y la ciencia, de la voluntad de dominio de la naturaleza" (Bianchi, $2015,42)$. Esta parte de la historia del feminismo ha sido olvidada. Actualmente, los Animal Studies y la Ética Animal son áreas de investigación emergente con una importante presencia en las investigaciones de vanguardia de la Academia. Pero como sucediera con otras áreas de conocimiento, se ignora u oculta que tiene una historia y unas bases (eco)feministas (Adams \& Gruen, 2014; Velasco Sesma, 2017). La compasión por los sufrimientos de los animales sigue siendo hoy un fenómeno más frecuente en mujeres que en varones, si bien un número creciente de éstos también la experimentan ${ }^{13}$. Y la conexión entre ecologismo y antiespecismo tiene también a las mujeres como protagonistas principales: "el ecologismo feminista se da, mayoritariamente, vinculado a su versión animalista" (Balza y Garrido, 2016, 302).

La preocupación de las proto-ecofeministas del XIX por el animal como desdichado objeto de la ciencia estaba acompañada de la conciencia de su relación con la construcción androcéntrica del sujeto de la ciencia: un sujeto marcado por un sesgo claramente patriarcal

11 La vivisección sin anestesia de un perro callejero marrón realizada por un profesor en su clase y denunciada por dos sufragistas.

12 Como señala L. Desblache (2011), el racionalismo impregna aún en nuestros días la cultura francesa, estableciendo mayor distancia entre los humanos y el resto de los seres vivos que la cultura anglófona, marcada por el Romanticismo. Para una revisión de las razones que llevan a la insistencia en el abismo ontológico en el campo de la Filosofía, ver C. Velayos (2013).

13 La conciencia ética ante el sufrimiento animal se halla en aumento. Y no sólo con referencia a la industria cárnica o a los laboratorios científicos, sino también atendiendo a otros ámbitos aparentemente menos crueles como los zoológicos. El supuesto objetivo didáctico de los zoológicos no se alcanza, ya que los seres allí aprisionados no son lo que eran en libertad. Marta Tafalla se pregunta cómo educar para que la atracción estética que despiertan los animales no lleve a encerrarlos y concluye: "procura que aquello que amas y admiras, que te fascina y te produce placer, no sea destruido por tu propia fascinación" (Tafalla, 2013, 90). La dominación conduce a un conocimiento falso. 
que en la compasión sólo veía una debilidad femenina. Comprendieron que la adhesión entusiasta a la práctica de la vivisección creaba un nuevo modelo de masculinidad violenta que ya no era el del hombre brutal sin instrucción, sino la calculada crueldad del científico en búsqueda de objetividad. Es la figura del "testigo modesto" teorizada por la tecnofeminista Donna Haraway como representativa de las transformaciones epistémico-productivas de la Modernidad (Haraway, 2004).

Todavía hoy, durante sus estudios, a los futuros médicos y veterinarios se les enseña a despreciar el sufrimiento y la vida de los animales de experimentación. Esta actitud se normaliza y pasa a formar parte de la rutina por la influencia de los profesores -que son modelos en el entrenamiento- y por la necesidad de los mismos estudiantes de bloquear los sentimientos para evitar la angustia generada por las prácticas que realizan. Así se va forjando su perfil profesional (Thomas, 2013), un perfil que en la época victoriana, advirtieron las sufragistas (Bianchi, 2015), creaba profesionales altivos, distantes y despreciativos que llegaban a reírse ante los sufrimientos de los animales de experimentación y de las mujeres pobres utilizadas en los hospitales como ejemplos en las clases de Medicina.

La inquisitio científica revela su pudenda origo en el imaginario de Francis Bacon y de otros hombres de su época. En Bacon, la Naturaleza aparece como mujer a la que hay que acosar para que se entregue al que la desea, útero al que hay que extraer la riqueza, bruja a la que hay que torturar para que revele sus secretos (Merchant, 1981). Se producía, así, el paso de la filosofía hermética de la antigua alquimia con su imagen del matrimonio entre el principio masculino y el femenino, el espíritu y la materia ${ }^{14}$, al conocimiento experimental de la Nueva Ciencia como dominio viril (Evelyn Fox Keller (1991). "For Bacon, as for Harvey, sexual politics helped to structure the nature of the empirical method that would produce a new form of knowledge an a new ideology of objectivity seemingly devoid of cultural and political assumptions" (Merchant, 1981, 172). Las violentas metáforas que emergen en esta época de transición mostraban que la separación sujeto/objeto no sería de mera contemplación. En la filosofía mecánica, el sujeto actuaría sobre el objeto reducido a mera extensión. La distancia infinita entre sujeto y objeto sería la de la indiferencia respecto a cualquier otra cualidad que no fuera relevante para los fines buscados. Más tarde, las prácticas de laboratorio encontrarían una justificación cómoda en la teoría del animalmáquina de Descartes. Los aullidos de dolor de las criaturas viviseccionadas no eran signos de que poseyeran sensibilidad. Según los cartesianos, eran un simple chirrido de la maquinaria. En los siglos XVII y XVIII, esta teoría encontró una enconada resistencia en las mujeres que la conocían. Robert Boyle cuenta que las "bellas damas" que asistían a los experimentos científicos en calidad de observadoras le habían obligado en alguna ocasión a detener su demostración de la producción de vacío con extracción de aire porque no soportaban ver agonizar los pájaros encerrados en la campana (Bowerbank, 2004). Para los miembros de las recientemente creadas sociedades científicas, este hecho constituía una confirmación de la incapacidad femenina para la investigación y una justificación más para la exclusión de las mujeres del conocimiento. Dominadas por los sentimientos, no eran aptas para el acceso al saber.

14 Como bien señala Fox Keller (1991), observar este cambio no significa sostener que los filósofos herméticos fueran feministas, sino que conservaban cierta reverencia hacia la fertilidad de la mujer y de la naturaleza. 
Observemos que la utilización de animales en experimentos de laboratorio no sólo ha sido cuestionada desde la perspectiva ética sino también desde su eficacia para generar conocimiento aplicable a los seres humanos. La experimentación en laboratorio se basa en la premisa de que los modelos animales son predictivos. Sin embargo, las investigaciones biomédicas distan mucho de confirmar tal suposición. Numerosos factores que van desde el stress sufrido en el laboratorio hasta las diferentes dosis necesarias para que un tóxico actúe o la variedad de canales que éste siga según las especies, generan un alto grado de incertidumbre ${ }^{15}$. Sin embargo, la rutina y la facilidad de estas prácticas explican los millones de animales que mueren todos los años en medio de terribles padecimientos. Su número no cesa de aumentar. La experimentación animal no se reserva para investigaciones trascendentes que supongan enormes avances para la curación de enfermedades. Cualquier motivo, hasta el más fútil, se considera suficiente para acudir a ella, si bien ha habido algunas restricciones legales en los últimos años como resultado de intensas campañas basadas en argumentos científicos y filosóficos. ${ }^{16} \mathrm{El}$ dualismo sujeto/objeto continúa articulándose con la división entre razón y emoción, bloqueando todo sentimiento empático que diera lugar a la compasión. Pero cabe preguntarse desde una perspectiva ecofeminista en qué medida otro tipo de emociones -las vinculadas a la voluntad de poder- están presentes en la falta de interés por desarrollar métodos alternativos que ya se conocen.

El desarrollo de la Ética del Cuidado en los años ochenta del siglo XX fortaleció al ecofeminismo que inmediatamente la adoptó, aunque dándole un sello propio. La interpretación ecofeminista de la ética del cuidado está encaminada a dar la voz a quienes no la tienen, en particular a los animales (Donovan, 2016). Contribuye, así, a corregir el antropocentrismo extremo que predomina aún en el conocimiento. La ecofeminista Donovan señala la similitud entre las teorías materialistas del punto de vista y la teoría del cuidado ${ }^{17}$. Afirma: "La teoría del cuidado es en el fondo una intervención política con el propósito de recuperar y articular voces suprimidas y marginadas (...) cuyo punto de vista forma las bases para una crítica ética y con el propósito de revelar, criticar y enfrentar al sistema que oprime" (Donovan, 2016, 65-66). Ambas funcionan como impugnaciones del punto de vista dominante.

Sin embargo, en algunas ecofeministas postmodernas, esta corrección del antropocentrismo dominante se ve muy debilitada por la asunción de un relativismo cultural que elogia la "caza relacional" de algunos pueblos originarios de América. La narrativa sioux, que entiende que el animal se ofrece al cazador y éste lo trata con respeto, es considerada como

15 Así, Andrew Night observa: "Las diferencias entre especies en las vías o las tasas de absorción, distribución, metabolismo y eliminación pueden, todas ellas, influir en la toxicidad química, incluso en la carcinogénesis. Dado que muchos carcinógenos deben ser metabolizados como electrófilos reactivos para que produzcan sus efectos cancerígenos, las diferencias entre especies en las vías o las proporciones pueden afectar a los niveles de actividad de los metabolitos cancerígenos" (Mi traducción). «Species differences in absorption, distribution, metabolism, and elimination pathways or rates can all influence chemical toxicity, including carcinogenicity. Since many carcinogens must be metabolised to reactive electrophiles to produce their carcinogenic effects, species differences in pathways or rates can affect activity levels of carcinogenic metabolites.» (Knight, 2011, 81)

16 El 11 de marzo de 2013, entró en vigor en la UE la prohibición total de la experimentación de productos cosméticos en animales. Con la prohibición de la comercialización de productos testados en animales, se completaba, así, un proceso iniciado en 2003.

17 Sobre la relación entre cuidado y responsabilidad con relación a los no humanos, ver López de la Vieja (2015). 
ejemplo de percepción afectiva de la naturaleza por Karen Warren, en un planteamiento que se coloca en las antípodas de la crítica de Collard (1988) a la caza como modelo de la ciencia. El sufrimiento del animal se diluye en un contextualismo radical seducido por las culturas no occidentales. La realidad material no humana captada desde el punto de vista compasivo ecofeminista desaparece.

En su búsqueda de una ciencia empática, la teoría ecofeminista ha puesto de relieve las investigaciones de Barbara McClinctock (Donovan, 2014). Esta citogenetista que descubrió los "transposones" - secuencias de ADN capaces de trasladarse de lugar dentro del genoma- insistía en la necesidad de escuchar a la materia, de abrirse a su enorme complejidad. Sostenía que era necesario mantener con el objeto una relación empática que permita la intimidad sin aniquilar la diferencia. Pero si hay un ejemplo absolutamente claro de las potencialidades de una actitud empática para la adquisición de conocimiento, éste es el de las primatólogas elegidas por Louis Leakey para estudiar los orígenes de nuestra especie: Dian Fossey, que fue asesinada por los cazadores por defender a sus "objetos" de estudio, los gorilas de montaña, Biruté Galdikas, que dedicó su vida a los orangutanes, y Jane Goodall que hizo lo propio con los chimpancés. Como ha destacado Marta I. González: "La primatología es una disciplina especialmente relevante para los estudios sobre ciencia y género, ya que en ella concurren varios factores de interés tanto para el estudio de las mujeres científicas como para el análisis de los efectos de valores de género sobre contenido y métodos" (González, 2004, 11).

Cuando inició sus observaciones en Gombe (Tanzania), J. Goodall transgredió una de las instrucciones metodológicas que se le habían dado. En vez de asignar un número a cada individuo del grupo de animales, les dio nombre. En su caso, no se trata de un detalle anecdótico. Darles un nombre era reconocer su estatus de sujetos de una vida, reconocerles y respetarles. El legado de estas tres primatólogas es inmenso, tanto en conocimiento de las especies estudiadas como en la innovación metodológica que implicó su actitud y su práctica y que hizo escuela (González, 2004; Rodríguez Carreño, 2012). No corresponde en este espacio recordar todos sus descubrimientos, pero a modo de ejemplo, señalaré que, gracias a la escucha empática, Jane Goodall es considerada la científica que ha cambiado la definición de nuestra especie. Hoy se reconoce que homo faber no es una descripción satisfactoria ya que Goodall descubrió que la fabricación y utilización de instrumentos se dan en otros primates. También sabemos, gracias a sus estudios, que la guerra organizada no nos es privativa. En la primatología, la aproximación empática logró lo que el estudio frío y distante de individuos numerados no había sido capaz de alcanzar.

El reduccionismo mecanicista de la ciencia moderna tampoco es capaz de comprender y tratar adecuadamente la complejidad ecosistémica, conduciendo así a una noción de desarrollo que es, en realidad, un "mal desarrollo" (Shiva, 1995). Durante la llamada Revolución Verde en la India, los expertos despreciaron el conocimiento de las plantas que tenían las campesinas y el resultado fue la desertización y el desequilibrio de los ecosistemas locales. Se impuso un monocultivo intensivo en una guerra contra la Naturaleza que destruyó la biodiversidad y la diversidad cultural, trayendo miseria y desplazamientos poblacionales. Baste este caso, entre otros muchos existentes, para afirmar que avanzar hacia una cultura de la sostenibilidad exige una concepción del conocimiento más democrática, intercultural y abierta a la experiencia de las mujeres. 


\section{A modo de conclusión}

La teoría ecofeminista mantiene una relación estrecha pero también tensa con las ciencias. Por un lado, su génesis está vinculada a ellas, en particular, a la Ecología, la Antropología y la Etología. Por otro, plantea importantes críticas al conocimiento hegemónico. Ha denunciado los efectos de la iatrogenia y de la contaminación ambiental en los cuerpos de las mujeres, así como los sesgos de género que limitaban las investigaciones médicas. Pero en un nivel aún más profundo, ha señalado que el paradigma epistemológico moderno de la separación sujeto/objeto y de la represión de los sentimientos imprime un sesgo androcéntrico a las prácticas consideradas científicas, favoreciendo una visión distorsionada y escindida de naturaleza y humanidad.

La crítica ecofeminista examina la epistemología bajo la luz de la filosofía moral y política en clave de género, mostrando los sesgos de sexo, clase, raza y especie que afectan a la pretendida objetividad científica. Con ello, no realiza un ejercicio ocioso de nihilismo. Su finalidad es ética y transformadora. En sus enfoques más prometedores, llevada por la urgencia de la crisis ecológica y por la compasión ante el sufrimiento de seres humanos y no humanos, busca una ciencia empática que no produzca un sujeto escindido y un objeto reducido a una sola de sus cualidades y dimensiones. Llama a una ciencia que sepa escuchar las voces del Otro, las voces de las y los oprimidos y que sepa aprender de los conocimientos excluidos.

Es importante subrayar que el objetivo de la crítica ecofeminista no ha de ser la destrucción de la ciencia y su sustitución por algún tipo de pensamiento místico que recorte los derechos de las mujeres. Reconocer saberes silenciados no implica la equiparación y aceptación de cualquier discurso. Es necesario mantener una postura que no sea ni tecnofóbica ni tecnólatra.

La crítica ecofeminista puede colaborar en el reencuentro de las ciencias sociales con las ciencias naturales, sin caer en el biologicismo ni en la disolución nominalista radical. Desde la experiencia de quienes vienen de una larga historia de opresión y de lucha por acceder al logos y ser reconocidas como sujetos, y en la escucha de otras culturas más respetuosas de la Naturaleza pero sin olvidar el legado ilustrado, la teoría ecofeminista posee un potencial inestimable para impulsar un conocimiento menos antropocéntrico, o, lo que es lo mismo, más ajustado a la diversidad del ser. Pero más allá de la epistemología, su crítica al androantropocentrismo es una invitación a que la ciencia y el conocimiento estrechen lazos con la ética para que un mundo sin dominación sea posible.

\section{Referencias}

Adams, C., Gruen, L. (2014): “Groundwork”, in Adams, C., Gruen, L. (eds.) (2014): Ecofeminism. Feminist Intersections with other Animals \& the Earth, New-York-London: Bloomsbury, pp. 7-36.

Amorós, C. (1997): Tiempo de feminismo. Sobre feminismo, proyecto ilustrado y postmodernidad, Madrid: ed. Cátedra, Col. Feminismos.

Balza, I., Garrido, F., (2016): “¿Son las mujeres más sensibles a los derechos de los animales? Sobre los vínculos entre el animalismo y el feminismo", en ISEGORÍA. Revista de Filosofía Moral y Política, $\mathrm{n}^{\circ}$ 54, enero-junio, pp. 289-305. 
Bianchi, B. (2015): “¿Es compatible la ciencia con la ética? El pensamiento de las sufragistas antiviviseccionistas del siglo XIX”, en A. Puleo, G.A. Tapia González, L. Torres San Miguel, A. Velasco Sesma, (coords.) (2015), Hacia una cultura de la sostenibilidad. Análisis y propuestas desde la perspectiva de género, Ed. Departamento de Filosofía de la Universidad de Valladolid y Cátedra de Estudios de Género, pp. 41-64.

Bowerbank, S. (2004): Speaking for Nature. Women and Ecologies of Early Modern England, Baltimore: The John Hopkins University Press.

Collard, A. (1988): Rape of the Wild, London: The Women's Press Limited.

D’Eaubonne, F. (1997): "La época del ecofeminismo", en: M.X. Agra (1997), Ecología y Feminismo, trad. A. C. Rodríguez Buján, Granada: Ecorama.

Desblache, L., La plume des bêtes. Les animaux dans le roman, Paris: L'Harmattan.

Donovan, J. (2014): «Participatory Epistemology, Sympathy, and Animal Ethics», en: C. Adams, L. Gruen (eds.) (2014), Ecofeminism. Feminist Intersections with other Animals \& the Earth, New-York-London: Bloomsbury, pp. 75-90.

Donovan, J. (2016): "La voz de los animales: una respuesta a la reciente teoría francesa del cuidado en ética animal", Revista Latinoamericana de Estudios Críticos Animales, Año III, Vol. II, pp. 63-84.

Fox Keller, E. (1991): Reflexiones sobre género y ciencia, trad. A. Sánchez, Valencia: Alfons el Magnànim.

Foucault, M. (1974): La volonté de savoir, I vol. Histoire de la sexualité, París: Gallimard.

García Dauder, S., Pérez Sedeño, E. (2017): Las 'mentiras' científicas sobre las mujeres. Madrid: Ed. de la Catarata, Colección Mayor.

González, M. I. (2004): “Creer para Ver: Primates, homínidos y mujeres”, en: VV.AA., Mujeres Pioneras, Col. La Historia no contada, Albacete: Editora Municipal-Instituto de la Mujer.

Guerra, M. J., "Un vínculo privilegiado mujer-naturaleza? Rachel Carson y el tránsito de la sensibilidad naturalista a la conciencia ecológica", en: M. L. Cavana, A. Puleo, C. Segura (coords.) (2004): Mujeres y Ecología. Historia, Pensamiento, Sociedad, Madrid: ed. Almudayna, pp. 119-127.

Rodríguez Carreño, J. (2012): "Frances Power Cobbe y la lucha contra la vivisección como causa femenina en la Inglaterra del siglo XIX”, en: J. Rodríguez Carreño (ed.), Animales no humanos entre animales humanos, Madrid: Colección Dilemata, Plaza y Valdés ed., pp. 85-116.

Haraway, D. (2004): Testigo_Modesto@SegundoMilenio.HombreHembra@_Conoce-Oncoratónâ. Feminismo y tecnociencia, trad. E. Torres, Barcelona: Ed. UOC.

Haraway, D. (2008): When Species Meet, Posthumanities, Volume 3, University of Minneapolis-London: Minnesota Press.

Hartsock, N. (1983): "The Feminist Standpoint. Developing the Ground for a Specifically Feminist Historical Materialism”, en: Harding, S., Hintikka, M., Discovering Rality. Feminist Perspectives on Epistemology, Metaphysics, Methodology, and Philosophy of Science, New York: Kluwer Academic Publishers, pp. 283-310.

Knight, A. (2011): The Costs and Benefits of Animal Experiments, Basingstoke, UK: Palgrave Macmillan. 
López de la Vieja, T. (2015): “Cuidado y responsabilidad”, en A. Puleo (ed.) (2015), Ecología y género en diálogo interdisciplinar, Madrid: Plaza y Valdés, Colección Moral, Ciencia y Sociedad en la Europa del siglo XXI, pp. 157-169.

Merchant, C. (1981): The Death of Nature: Woman, Ecology, and the Scientific Revolution, San Francisco: Harper and Row.

Mies, M., Shiva, V., (1998), La praxis del ecofeminismo. Biotecnología, consumo y reproducción, trad. M. Bofill y D. Aguilar, Barcelona: Icaria.

Ortner, S. (1972): "Is Female to Male as Nature is to Culture?", Feminist Studies, Vol. 1, No. 2 (Autumn, 1972), pp. 5-31.

Ortner, S. (1996): Making Gender: The Politics and Erotics of Culture, Boston: Beacon Press, 1996, pp. 173-180.

Puleo, A.H. (2000): Filosofía, Género y Pensamiento Crítico, Servicio de Publicaciones de la Universidad de Valladolid.

Puleo, A.H. (2011): Ecofeminismo para otro mundo posible, Madrid: ed. Cátedra, Col. Feminismos.

Pérez Sedeño, E., Ortega Arjonilla, E. (eds.) (2014): Cartografías del cuerpo. Biopolíticas de la ciencia y la tecnología, Madrid: ed. Cátedra, Col. Feminismos, pp. 7-46.

Prendergast, B.J., Onishi, K.G., Zucker, I. (2014): «Female mice liberated for inclusion on neuroscience and biomedical research», Neuroscience \& Biobehavioral Reviews, vol. 40, March, pp. 1-5.

Roldán, C. (2013): "Ni virtuosas ni ciudadanas: inconsistencias prácticas en la teoría de Kant”, Ideas y valores, vol. LXII, suplemento n ${ }^{\circ}$ 1, Bogotá, pp. 185-203.

Shiva, V. (1995): Abrazar la vida. Mujer, ecología y desarrollo, trad. Instituto del Tercer Mundo de Montevideo (Uruguay), Madrid: ed. horas y Horas.

Tafalla, M. (2013): "La apreciación estética de los animales. Consideraciones estéticas y éticas”, en Revista de Bioética y Derecho no 28, pp. 79-90.

Thomas, J. (2013): «Unpatients: The Structural Violence of Animals in Medical Education», Journal for Critical Animal Studies, Volume 11, Issue 1, pp. 46-62.

Traïni, C. (2011): La cause animale. 1820-1980. Essai de sociologie historique, Paris: Presses Universitaires de France.

Valls-Llobet, C. (2009): Mujeres, salud y poder, Madrid: ed. Cátedra, Col. Feminismos.

Valls-Llobet, C. (2015): "Sesgos de género en medio ambiente y salud", in A. Puleo (ed.) (2015), Ecología y género en diálogo interdisciplinar, Madrid: Plaza y Valdés, Colección Moral, Ciencia y Sociedad en la Europa del siglo XXI, pp. 21-35.

Velasco Sesma, A. (2017): La Ética Animal. ¿Una cuestión feminista?, Madrid: ed. Cátedra, Col. Feminismos.

Velayos, C. (2013): "La frontera animal-humano", Arbor no 763, pp. 1-11.

Warren, K. (1996): "The power and the Promise of Ecological Feminism", en: Warren, K. (ed.) Ecological Feminist Philosophies, Bloomington and Indianapolis: Indiana University Press, pp. 19-40. 